\title{
浸潤性膀胱癌に対するマイクロ波凝固術の治療効果
}

\author{
由利康裕, 原田 忠, 木暮 輝明, 下田 次郎, \\ 松川 秀樹, 福田 孝*，吉田 公基*
}

\section{Clinical efficacy of microwave regional coagulation therapy on invasive urinary bladder cancer}

\author{
Yasuhiro Yuri, Tadashi Harada, Teruaki Kigure, Jiro Shimoda, \\ Hideki Matsukawa, Takashi Fukuda * and Kouki Yoshida*
}

\begin{abstract}
In our clinic, since 1985 transurethral microwave regional coagulation therapy (MRC) has been performed for patients with urinary bladder cancer as a bladder preserving procedure. The survival rate and the prognostic significance of clinical and pathological variables were investigated in 29 patients who had undergone MRC to invasive urinary bladder cancer (T2, T3NOMO). The prognosis of the patients resulted in the survival rate of $68 \%(\mathrm{G} 1, \mathrm{G} 2: 80 \%, \mathrm{G} 3: 51 \%)$ after 5 years. Six patients died of cancer. Five of these patients had G3 cancer. The death rate of patients with G3 cancer was significantly higher than those with G1 and G2 cancers. With MRC the preservation rate of the urinary bladder was $79 \%(23 / 29)$. In conclusion, these results indicate that we might be able to treat the invasive urinary bladder cancer without total cystectomy, applyting MRC to that of G1 and G2.
\end{abstract}

Key words : Microwave, Microwave coagulation, Invasive bladder cancer, Clinical evaluation, Prognosis

秋田大学医学部 泌尿器科学教室 干010 秋田市本道 1-1-1

Department of Urology, Akita University School of Medicine

Address : 1-1-1, Hondo, Akita, 010, Japan

秋田労災病院 泌尿器科* 干 018-56 大館市軽井沢字下岱 30

Department of Urology, Akita Rosai Hospital

Address : 30, Shimotai, Karuizawa, Odate, Akita, 018 -56, Japan 


\begin{tabular}{lccc}
\hline & Ta, T1 NOMO & T2, T3NOMO & 有 意 差 \\
\hline 症例数 & 79 & 29 & なし \\
年令 & $62.5 \pm 10.0$ & $65.5 \pm 11.1$ & なし \\
男 女 & $58 / 21$ & $26 / 3$ & なし \\
初発 $/$ 再発 & $46 / 33$ & $18 / 11$ & なし \\
単発 /多発 & $29 / 50$ & $8 / 21$ & なし \\
乳頭状 /非乳頭状 & $73 / 6$ & $13 / 16$ & $\mathrm{p}<0.01$ \\
観察期間 (月) & $53 \pm 19$ & $43 \pm 22$ & なし \\
\hline
\end{tabular}

\section{緒言}

表在性膀胱癌に対しては，経尿道的膀胱腫瘍 切除術を中心とした膀胱保存療法が広く行われ ている。しかし，浸潤性膀胱癌に対する根治療 法としては, 膀胱全摘術兼尿路变更術が一般的 である。近年, 浸潤性膀胱癌に対しても, 膀胱 機能や性機能をできるだけ温存し，かつ根治性 の高い治療法の確立が望まれている。筆者ら は，これまで膀胱癌に対してマイクロ波による 腫瘍の凝固療法を施行し，その成績を報告して きた ${ }^{1-4)}$ 。今回は，主として浸潤性膀胱癌に対 するマイクロ波凝固術の治療成績をまとめ，そ の膀胱保存療法としての可能性について検討し た。

\section{対象および方法}

1985年1月より当教室に扔いてマイクロ波凝 固術を施行した膀胱癌のうち, リンパ節転移や 遠隔転移を認めない表在性腫瘍（Ta，T1NOMO ） 79 例，および浸潤性腫瘍（T2， T3NOMO）29例を対象とした（表1）。患者の

\section{表2 深達度と悪性度}

\begin{tabular}{ccc}
\hline Grade & Ta, T1NOMO & T2, T3NOMO \\
\hline G1 & 31 & 3 \\
G2 & 40 & 12 \\
G3 & 8 & 14 \\
\hline
\end{tabular}

背景因子を見ると，浸潤性膀胱癌において非乳 頭状腫瘍の占める割合が有意に高かった。

また，悪性度別では，浸潤性腫瘍において high grade 症例の割合が有意に高かった（表 2)。

経尿道的マイクロ波凝固術は，これまで報告 してきたようにマイクロ波発振装置として Microtase HS-15M (平和電子製) を, 凝固用 プローブとして外径 $3.5 \mathrm{~mm}$ の同軸ケーブルか らなるモノポーラアンテナ型電極を使用して行 った。通常, 硬膜外麻酔または腰椎麻酔のもと, $25 \mathrm{Fr}$ の膀胱鏡観察下にプローブ先端を腫瘍に 密着させ, 周波数 $2450 \mathrm{MHz}$, 出力 100 ワットで 腫瘍を凝固した。腫瘍の大きさが $1 \mathrm{~cm}$ 未満と小 さい場合は 30 秒間程度のマイクロ波照射で凝 
固は完了するが，腫瘍が大きい場合や多発性の 場合には，プローブを移動させ同様の操作を繰 り返した。

浸潤性膀胱癌症例 29 例のうちマイクロ波凝 固術を単独で施行したのは 10 例であり, 他の 19 例に対しては平均 $34 \mathrm{~Gy}$ の膀胱腔内コバルト 照射法 ${ }^{5)}$ を併用したが，この19例はおもに多発 性あるいは再発性の腫瘍であった。

治療後には，原則として 2 週間以内に膀胱鏡 検査, 尿中細胞診, 膀胱生検を行い, 残存腫瘍 のないことを確認した。また，その後の経過観 察中には，2-4 週毎の尿中細胞診，3 月毎の膀 胱鏡検査, および必要に応じて生検, 超音波検
査，CTなどを行った。

\section{結果}

浸潤性膀胱癌症例 29 例に対するマイクロ波 凝固術の成績を表 3 に示す。このうち，N.E.D. の症例は平均観察期間 52 ヶ月現在で 21 例であ った。また，現在でも膀胱が保存されている症 例は 17 例 $(81 \%)$ であった。死亡例は 8 例で, このうち癌死が 6 例, 他因死が 2 例であった。癌 死症例 6 例のうち 5 例は G3 であった。

Kaplan-Meier 法による生存曲線を図 1 に示 す。Ta, T1NOMOの 5 年生存率は $82 \%$ であっ たのに対し，T2，T3MONOでは $68 \%$ であり，

表 3 浸潤性膀胱癌に対するマイクロ波凝固術の成績

\begin{tabular}{lcccccc}
\hline & 例 数 & G1 & G2 & G3 & 年 齢 & 観察期間 (月) \\
\hline N. E. D. & 21 & 2 & 11 & 8 & $64 \pm 12$ & $52 \pm 21$ \\
Dead of Ca & 6 & - & 1 & 5 & $68 \pm 5$ & $16 \pm 7$ \\
Dead of non Ca & 2 & 1 & - & 1 & $77 \pm 7$ & $29 \pm 26$ \\
\hline
\end{tabular}

N. E. D. : no evidence of disease

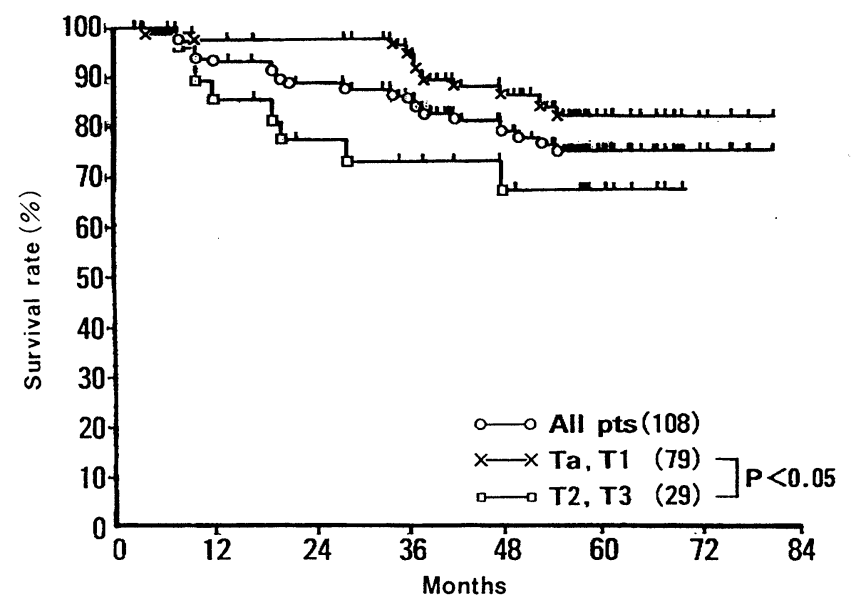

図 1 表在性および浸潤性膀胱癌症例の生存曲線 
両群間には generalized Wilcoxon 検定で有意 差を認めた。

一方，T2，T3の浸潤性腫瘍に㧍ける悪性度別 の 5 年生存率は, G1+G2 で 80 \%であったのに 対して, G3では51\%と有意に低值を示した(図 2)。

図3にKaplan-Meier 法による非再発曲線を
示す。Ta, T1と T2, T3との間にはほとんど差 はなく, 108 例全体の 5 年非再発率は $67 \%$ であ つた。

非再発率を T2, T3に限ってみると, 29 例全 体では 5 年非再発率は $64 \%$ \%゙あり, 悪性度の違 いによる有意差を認めなかった（図 4)。さら に, 腫瘍の形態, 大きさ, 個数あるいは初発再

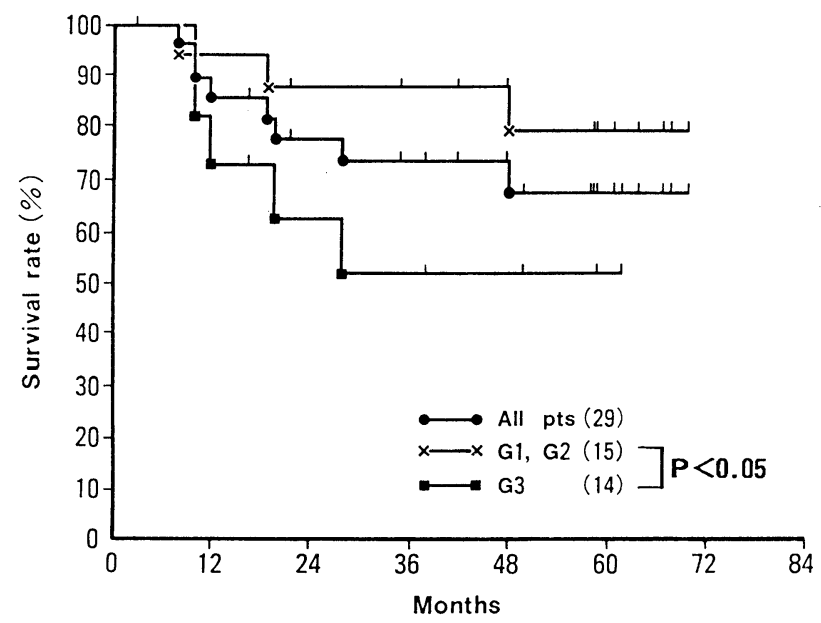

図2 浸潤性膀胱癌症例の悪性度別生存曲線

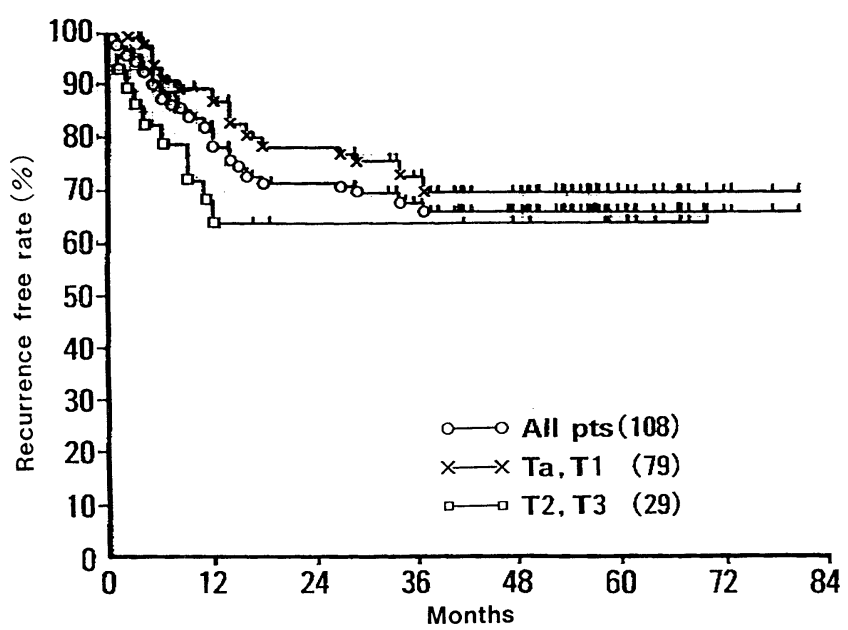

図 3 表在性および浸潤性膀胱癌症例の非再発曲線 


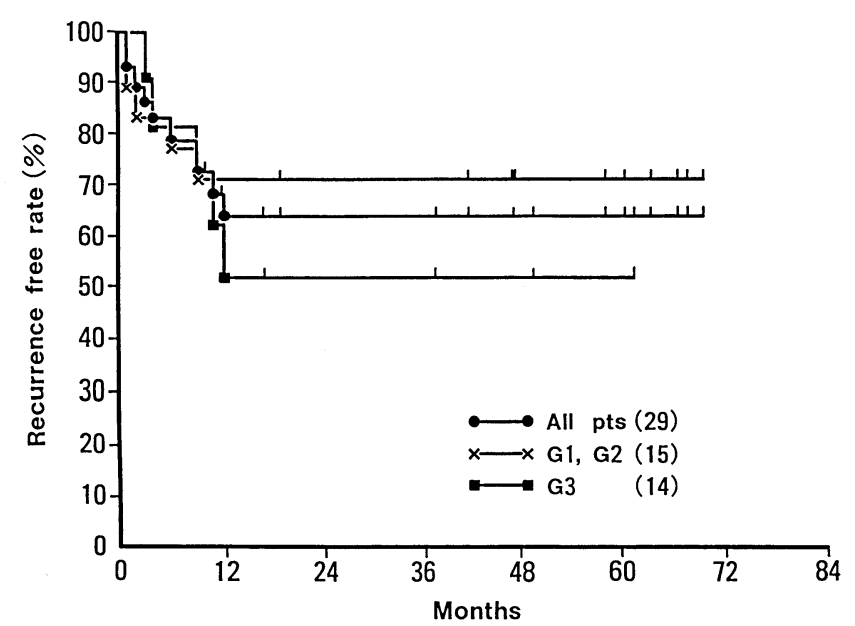

図 4 浸潤性膀胱癌症例の悪性度別非再発曲線

\section{表 4 副作用}

\begin{tabular}{lc}
\hline & 症例数 $(\%)$ \\
\hline 頻尿 & $15(52 \%)$ \\
排尿痛 & $4(14 \%)$ \\
血尿 & $2(7 \%)$ \\
萎縮膀胱 & $2(7 \%)$ \\
水腎症 & $1(3 \%)$ \\
膀胱結石 & $1(3 \%)$ \\
\hline 副作用あり & $17(59 \%)$ \\
\hline
\end{tabular}

発別に非再発率を検討したが，有意な差を認め なかった。

本治療法による副作用を表 4 に示す。最も多 かったのは一過性の頻尿であり，約半数の15例 に認めた。また，排尿痛 4 例 $(14 \%)$ ，血尿 2 例 （7％）を認めたほか，晚期副作用として萎縮膀 胱を 2 例に認め，この2例には膀胱全摘術を施行 した。また，水腎症を1例に認めたが，増悪傾向 がないため経過観察中である。

\section{考察}

浸潤性膀胱癌に対する根治療法は膀胱全摘術 が一般的であり，その5年生存率は 50 \%ないし それ以下と報告されている ${ }^{6-8)}$ 。膀胱全摘術後 には，膀胱機能および性機能の变失を避けるこ とができず，さらに通常は尿路変更に伴いス トーマが形成されることとなる。これによる患 者およびその家族の肉体的，精神的負担が問題 となる。また，膀胱全摘術および尿路変更術は 侵襲が大きいため，患者の全身状態あるいは合 併症によっては施行不可能なこともある。

以上の観点より膀胱をできるだけ保存し，な おかつ根治性の高い治療法が望まれる。筆者ら は病理組織学的な検討により，マイクロ波凝固 による抗腫瘍効果が膀胱の筋層深部まで及ぶこ とを確認している゙。今回の検討では，マイク 口波凝固術による膀胱保存的治療を施行した浸 潤性膀胱癌 29 例の 5 年生存率は $68 \%$ であった。 症例数や背景因子などの問題があるため, 諸家 
の報告と単純に比較することはできないが, 比 較的良好な成績と思われた。さらに，対象とな つた 29 例中 23 例 $(79 \%)$ では膀胱を保存する ことができ，患者のquality of lifeから見ても， マイクロ波凝固術の意義があったと考えられ る。

一方，膀胱癌死を 6 例 $(21 \%)$ に認め，この うち 5 例は G3 であり，G1，G2に比べ G3 の癌 死亡率が有意に高かった。G3 の浸潤性膀胱癌 に対しては集学的治療が必要と考えられる。

今回の検討で, G1+G2 の浸潤性膀胱癌の 5 年生存率は 80 \%と良好であり，G1, G2 の浸潤 性膀胱癌に対しては, マイクロ波凝固術による 膀胱保存的治療の可能性が示唆された。

\section{結語}

浸潤性膀胱癌（T2,T3NOMO）29例に対し， マイクロ波凝固術による膀胱保存的治療を施行 し，その 5 年生存率は $68 \%(\mathrm{G} 1, \mathrm{G} 2 ： 80 \%$, G3 : $51 \%$ ) であった。膀胱癌死を 6 例に認め, このうち 5 例はG3であり, G1, G2 に比べG3の 癌死亡率が高かった。本療法による膀胱保存率 は平均観察期間 52 力月現在 $79 \%(23 / 29)$ で あり，特にG1，G2の浸潤性膀胱癌（T2,T3NOMO）に対し, 本療法による膀胱保存的治療 の可能性が示唆された。

\section{文献}

1) 原田 忠: マイクロ波の泌尿器科疾患への応用. 第 2 報, 膀胱癌に対する経尿道的マイクロ波凝 固法. 日泌尿会誌, $78: 2180-2188,1987$.

2) Harada, T., Nishizawa, O., Miyagata, S., Etori, K., Kigure, T., Koh, D., Shimoda, J. and Tsuchida, S. : Microwave coagulation therapy for urinary bladder tumors. Urol. int., $43: 179-184,1988$.

3）木暮輝明, 原田 忠, 宮形 滋, 熊崎 匠, 本 郷隆二, 高 大輔, 下田次郎, 吉田公基, 佐藤 良延, 土田正義：マイクロ波凝固療法を中心と した膀胱癌の治療成績. マイクロウェーブ・サー ジェリー, 8:57-60, 1990.

4) 由利康裕, 原田忠, 宮形 滋, 木暮輝明, 吉 田公基, 下田直威, 土田正義：膀胱腫瘍に対す るマイクロ波凝固療法の病理組織学的検討. J. Microwave Surg., 10 :25-33, 1992.

5)原田 忠: Remote afterloading system (RALS) を用いた膀胱癌に対する腔内全粘膜照 射, 照射方法および治療効果予報. 日泌尿会誌, $78: 1907-1913,1987$.

6) Whitmore, W.F., Jr., Batata, M. A., Choneim, M. A., Grabstald, H. and Ural, A. : Radical cystectomy with or without prior irradiation in the treatment of bladder cancer. J. Urol., 118: 184-187, 1977.

7) Prout, G. R., Jr.: Classification and staging of bladder carcinoma. Cancer, suppl., 7, 45: 1832-1891, 1980.

8) Montie, J. E., Straffon, R. A. and Stewart, B. H. : Radical cystectomy without radiation therapy for carcinoma of the bladder. J. Urol., 131 : 477-482, 1984. 